Mirai. Estudios Japoneses

ISSN-e: 2531-145X

http://dx.doi.org/10.5209/MIRA.60494

\title{
Nihon Sankei: historia, arte, turismo. En torno a la identidad
}

\author{
Pilar Cabañas Moreno ${ }^{1}$
}

Fechas.

Resumen. Esta investigación plantea cómo una nueva lectura del paisaje de Matsushima, Amanohashidate y Miyajima, el llamado Nihon Sankei, basada en la construcción cognitiva del ser humano desde la perspectiva relacional, apoyándonos en los posicionamientos de la psicología social de Kenneth J. Gergen. Desde esta mirada el Nihon Sankei y su proceso de construcción identitaria nacional, siguiendo lo que Ikegami Eiko denomina cognitive associational map, "alcanza pleno significado.

Palabras claves: relacional; souvenir; arte japonés; identidad; mapa cognitivo

\section{[en] Nihon Sankei: History, Art, Tourism and Identity}

\begin{abstract}
This research offers a new reading of Nihon Sankei, a term that encompasses the landscapes of Matsushima, Amanohashidate and Miyajima. This reading is based on the cognitive construction of the human being, from the relational perspective relying on the social psychology perspective by Kenneth J. Gergen, and following the idea of "cognitive associational map" by Ikegami Eiko. Under this perspective, the relevance of Nihon Sankei in the configuration of Japan's national identity acquires its full meaning.
\end{abstract}

Keywords: relational; souvenir; Japanese art; identity; cognitive map

Cómo citar: Cabañas Moreno, P. (2018). Nihon Sankei: historia, arte, turismo. En torno a la identidad, en Mirai. Estudios Japoneses 2(2018), 35-48.

Si hoy tecleamos en los buscadores de internet el término Nihon Sankei, la pantalla se nos llenará de páginas que nos ofrecen maravillosos viajes a través de tentadoras y espectaculares imágenes de tres lugares de la geografía japonesa que a lo largo de la historia han sido ensalzados por la literatura y se han constituido en protagonistas de las artes plásticas, estando presente su representación incluso en los jardines, pero detrás de ellos hay mucho más que belleza. ¿Por qué? porque el paisaje no es simplemente un telón de fondo, un escenario ajeno a nosotros donde algo sucede. Sino que es más bien un espejo, tanto de quien contempla, como de la vida de las personas que habitualmente lo escuchan y lo hacen respirar. Y es

\footnotetext{
$1 \quad$ Universidad Complutense de Madrid pcabanas@ucm.es

Esta investigación ha sido realizada gracias a la ayuda de la Fundación Kajima, que me permitió recorrer los tres lugares de referencia llamados Nihon Sankei, y recoger la información requerida.
} 
que todos tenemos un paisaje en el que aprendimos a ser nosotros mismos, al que estamos enraizados.

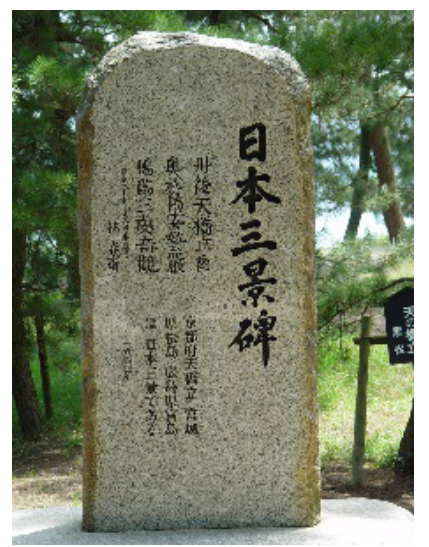

Fig. 1, Estela dedicada al Nihon Sankei, en Amanohashidate, ciudad de Miyazu, prefectura de Kioto. C (Pilar Cabañas, 2008)

Desde esta perspectiva el paisaje es parte esencial de nuestro patrimonio, tanto en el sentido más personal, como en el social. El paisaje es algo construido, ya sea por la propia naturaleza o por el hombre. No es algo intrínsecamente nuestro, que poseamos sin más, sino que es un legado a preservar para las nuevas generaciones. Es parte de nuestro patrimonio, tanto material como inmaterial. Con este deseo han surgido a lo largo de los siglos distintas categorizaciones como "Patrimonio cultural de la Humanidad", o "Parques Naturales". En Japón incluso existe la de "Tesoro Nacional Viviente", que engloba a aquellos artesanos y artistas, que pueden ayudar a preservar una tradición y destacados conocimientos en una determinada materia, el patrimonio inmaterial.

Así, en esa construcción, las distintas culturas se han definido alrededor de un paisaje. Los beduinos, moradores del desierto, entre dunas y oasis, los esquimales en medio de amplios horizontes helados, o el mundo subsahariano alrededor de elefantes y leones, animales que lo habitan y forman parte de él. Evidentemente, sin particularizar, caemos en generalizaciones y tópicos, pero la realidad es que, no importa cuánto vayamos de lo general a lo particular, que el hombre se define en función de su entorno, y cuando nos desplazamos con el deseo de conocer otros lugares, nos convertimos en turistas buscando disfrutar y comprender realidades distintas a la nuestra, rompiendo con nuestro espacio-tiempo cotidiano. ${ }^{2}$

Entendiendo el humano como un ser relacional, dentro de la psicología social, Kenneth J. y Mary Gergen, ${ }^{3}$ plantean que toda inteligibilidad humana (incluidas las reclamaciones al conocimiento) se genera dentro de las relaciones, siendo a partir de estas relaciones que los seres humanos obtienen sus concepciones de lo real, racional y bueno. Incluso en lo relacionado con el lenguaje, este no tiene significado por sí mis-

2 Nenzi, Laura (2008): Excursions in Identity: Travel and the Intersection of Place, Gender and Status in Edo Japan. Honolulu: University of Hawai'i Press.

3 Gergen, Kenneth J. / Gergen, Mary (2011): Reflexiones sobre la construcción social. Buenos Aires: Ediciones Paidós. 
mo, si no que deviene del su uso social. Por ello planteamos que desde el periodo Edo, en que el conocimiento relacionado con su entorno geográfico y político se populariza gracias al viaje y la lectura, este se dilata gracias y a través de una red de relaciones y asociaciones, que, además, si se desarrollan sobre la empatía con otros individuos con los que se descubren tener lazos comunes, genera la idea de pertenencia a una colectividad. Es desde esta comprensión del ser humano y su crecimiento personal y social, desde donde entender la entidad y el constructo del Nihon Sankei.

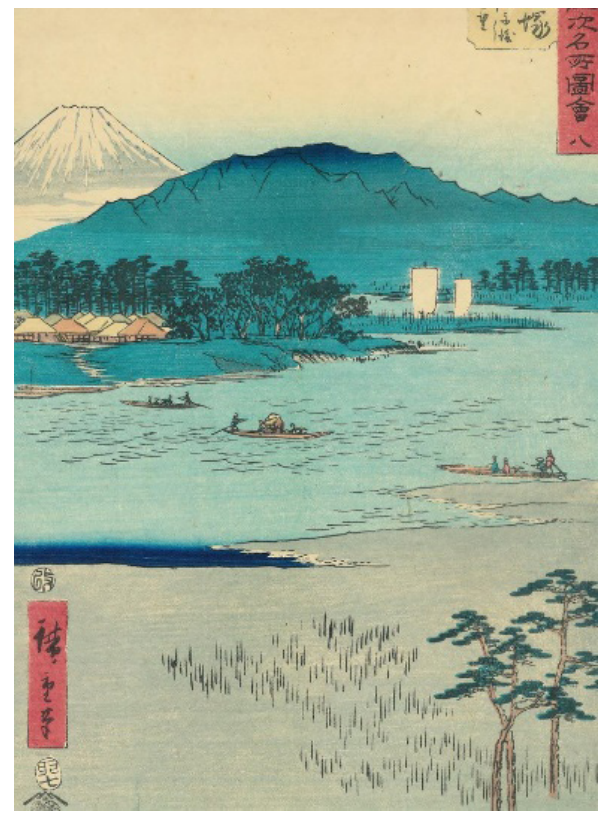

Fig. 2, Andō Hiroshige (1797-1858). Estación 8, Hiratsuka, serie 53 estaciones de Tōkaidō. Editado por Tsutaya, 1855. Col. Emilio Bujalance.

Si miramos hacia Japón y nos situamos en el año 1615, cuando los Tokugawa consiguen reducir el castillo de Osaka, el último baluarte que se oponía a su legitimidad en el poder, observamos que comienza la configuración de sus territorios como nación. Fue por tanto durante el periodo Edo cuando, frente a lo que hasta entonces no había sido más que una imagen indefinida, empieza a dibujarse un nuevo horizonte en el paisaje japonés. De hecho, aunque el término Nihon o Nippon, había constituido durante siglos el nombre oficial del conjunto de territorios que reconocían la figura del emperador, se inició su popularización en el siglo XVII, gracias a la divulgación que, del nombre, asociado a la imagen de la forma del conjunto del territorio y su composición, se hizo en las publicaciones comerciales del momento. Esto facilitó que prosperara la consideración popular de pertenencia a una entidad más amplia que la de su propio entorno. Es un hecho que, con anterioridad, la mayoría de los mapas de Japón estaban dibujados tal y como se configuraban en la mente de sus habitantes, como un conglomerado de territorios, unos adyacentes a otros, sin tan siquiera una línea periférica que los uniera como conjunto. Como ejemplos podemos citar modelos de diversas épocas como el Mapa de Japón del templo Ninna de Kioto (1306) y el Dai Nihon koku zu o Mapa del Gran Japón (1548). Japón, como 
unidad, fue cristalizando a lo largo del periodo Edo, siendo esto de gran relevancia para el tema que nos ocupa.

La sociedad urbana del momento y sus múltiples demandas culturales, entre las que estaban la lectura y el viaje, contribuyeron de un modo natural y orgánico a generar una identidad común, construyendo lo que Ikegami Eiko denomina cognitive associational map, ${ }^{4}$ un concepto clave para entender el planteamiento y conclusiones de esta investigación.

El alto nivel de alfabetización permitió el gran desarrollo de las editoriales, algo que denotaba el desarrollo cultural alcanzado bajo los Tokugawa. Resulta destacable que estas publicaciones, que buscaban atraer al mayor número de público posible, hicieron también realidad la popularización de un lenguaje estético a través de las estampas, cuyo legado está presente en el manga y el anime actual. Además, la inquietud del público por introducirse en el conocimiento y práctica de la poesía, así como en las normas de etiqueta y buenos modales, hicieron de los libros dedicados a ello unos bestsellers, y a través de su lectura la gente del periodo Edo pudo desarrollar una serie de asociaciones con elementos del pasado vinculados a las artes, la historia o la literatura, que tenían que ver con el mapa territorial y conceptual de Japón. De un modo natural esta construcción tuvo el relevo en las nuevas generaciones de escritores, que suponían ya el conocimiento de los principales personajes o episodios de la tradición clásica, para poder hacer referencias, en ocasiones a modo de parodias, en las que los lectores hallaban gran fruición. Es un hecho, que estos nuevos lectores, probablemente por su limitada formación, no pudieran acceder a la lectura directa de los clásicos, pero, aun así, conocieron a sus protagonistas, sus hazañas y los lugares más significativos a los que estaban ligados.

Visitar esos lugares se convirtió en un deseo, que parecía hecho a medida de la sociedad urbana del momento. Como alternativa surgieron numerosas series de grabados que lo recreaban. Bien dispuesta al placer y al disfrute, los habitantes de las grandes ciudades convirtieron el viaje en un acto sociocultural mediante el cual romper con lo ordinario, siendo un aliciente, no solo el punto de destino, sino el camino mismo, lo que explica la ingente cantidad de negocios y servicios surgidos a lo largo de las rutas más transitadas que invitaban a desacelerar.

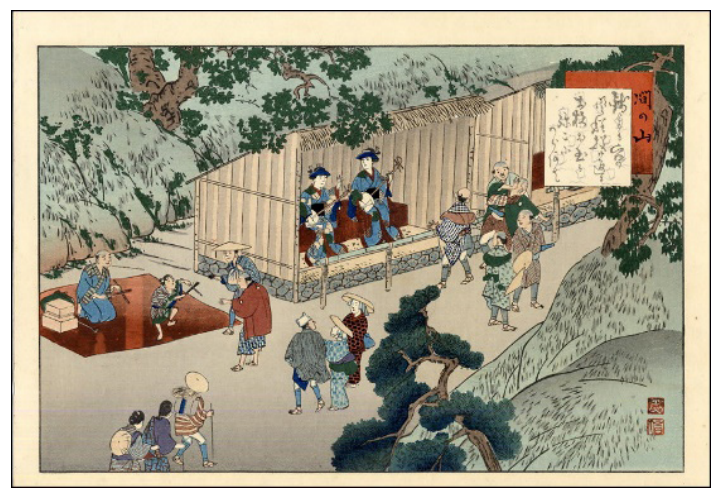

Fig. 3, Fujikawa Tamenobu (activo 1890-1910). Estación de Ainoyama, serie Famosos lugares del Tokaido, 1890. Nishiki-e. Col. Emilio Bujalance.

$4 \quad$ Ikegami, Eiko (2005): Bonds of Civility Aesthetic Networks and the Political Origins of Japanese Culture. New York: Cambridge University Press, pp. 371-372. 
Las editoriales, atentas a la demanda de estos deseos, proporcionaron ya mediado el periodo Edo, una abundante oferta de guías, que difundían en sus páginas una relación actualizada de todo tipo de servicios, siendo las más numerosas las ilustradas de la ruta del Tōkaidō, del Kisokaidō, de Ise, así como distintos caminos de peregrinación.

Con frecuencia estas publicaciones recogían variadísima información con ilustraciones, lo que les invitó a pensar en su propio país como en un lugar de inigualable belleza, con populosas y prósperas ciudades, pintorescos paisajes, templos y santuarios, todo ello inmortalizado, como hemos apuntado, por la historia o la literatura. Las primeras guías de viajes adoptaron una forma estándar de descripción enumerativa, a través de los listados donde aparecía lo que uno "no podía perderse", emergiendo así un perfil elocuente de la sociedad del momento. Por el carácter pragmático de los ciudadanos del momento, se dejaron de lado las antiguas publicaciones, que tenían un tono más literario, para ofrecer de manera prioritaria información más útil y actualizada de dónde alojarse, condiciones de los caminos, o qué comer, complementada por algún detalle histórico del lugar o alguna alusión poética a él. Todo acompañado de ilustraciones xilográficas, ideal para proporcionar mapas o la publicidad de determinados locales. Pero lo más importante era decidir dónde ir, y una categorización consensuada ayudaba a ello.

Con el nombre de Nihon Sankei (Los tres paisajes de Japón), los japoneses han priorizado tres paisajes, por importantes, bellos, grandiosos, etc. sobre el resto del país: Matsushima, Amanohashidate y Miyajima. Y ha sido con el transcurrir del tiempo, que fueron cargándose de significados hasta convertirse en los símbolos de identidad japonesa que son hoy. Conocidos por la élite culta, no se popularizaron hasta el periodo Edo (1600-1868), como ya hemos explicado, gracias a las publicaciones xilográficas, un medio de comunicación de masas de gran alcance.

Hay un término japonés que se repite en estas publicaciones: meisho, literalmente "lugar o lugares famosos", que frecuentemente están asociados con referencias poéticas o literarias, tan famosas, como La historia del príncipe Genji, de comienzos del siglo X, Cantares de Ise, una compilación del siglo X, o Historia de los Heike de los inicios del siglo XIII.

En la mayor parte de los casos, estos lugares tienen relación con obras literarias del periodo Heian (794-1185), un periodo de dominio aristocrático, y relativamente pocos con obras de periodos posteriores. Los aludidos lugares, fueron recuperados y citados en el periodo Edo en los dramas de teatro, ya sea el nō, el kabuki o el bunraku, popularizándose aún más gracias al grabado y a otras formas visuales del arte. Todo ello nos indica que estos lugares geográficos han alcanzado dicha categoría, meisho, al convertirse en paisajes, al convertirse en una construcción cultural.

Era al ser conocidos por sus resonancias poéticas y plásticas que mucha gente acudía expresamente para contemplarlos, o se detenía en su viaje de camino a otro lugar. Este es el caso por ejemplo de la costa de Suma, cerca de la actual playa de Kobe, donde tuvo lugar la gran batalla de Ichi no tani, y que teniendo relación con la lucha entre los clanes Taira y Minamoto, recogida en la mencionada Historia de los Heike, aparece incorporada a posteriores obras de teatro.

Por tanto, en el caso japonés de los meisho, es fácil advertir como afirma W.J.T., Mitchell, que el paisaje debe ser leído como un palimpsesto, pues no se limita a ser una vista panorámica, sino que está recubierto de múltiples escrituras. Esto entra dentro de las aproximaciones postmodernas al paisaje, en las que se entiende este 
también desde su importancia histórica, otorgándole una categoría material, conceptual y simbólica. ${ }^{5}$ En gran medida la actual gestión turística considera que el potencial de un lugar radica en conseguir generalizar el deseo de conocer todos y cada uno de sus estratos entre el mayor número de público posible.

De entre los llamados meisho, los Nihon Sankei, son un perfecto ejemplo para ilustrar esta construcción social del paisaje. Matsushima y Amanohashidate eran ya bien conocidos en la aristocrática corte de Heian, desde mediados del siglo XI, siendo entonces tema frecuente de muchos de sus poemas y de sus pinturas de lugares famosos (meisho-e). Y por otro lado Miyajima, una isla cerca de Hiroshima, que se hizo famosa a finales del siglo XII, cuando Taira Kiyomori, gobernador de Aki, construyó el santuario de Itsukushima en 1146 buscando la protección de los kami para su comercio con China.

Fue durante el periodo Edo, a raíz del desarrollo de los viajes y de las carreteras cuando comenzaron a conocerse los tres asociados. ${ }^{6}$ El primero que se sabe hasta ahora que dejó constancia de ello por escrito, fue el erudito neoconfuciano Hayashi Shunsō (1618-1680) ${ }^{7}$, quien tras realizar un viaje a pie por el país, recogió sus impresiones y experiencias en un libro titulado Nihon kokuji sekikō (Impresiones y pensamientos sobre la nación japonesa, 1643). En la documentación publicada para facilitar los viajes, en los llamados fudoki, ${ }^{8}$ habían aparecido referidos primeramente como San shoki kan ${ }^{9}$, y en el siglo XVIII se mencionaban en el Wakun no shiori, (Diccionario de lectura japonesa de idogramas chinos). ${ }^{10}$ Entre sus palabras surgen elogios sin reservas sobre estos tres lugares que, a su juicio, eran los más destacables de toda la nación.

La primera vez que aparece el término Nihon Sankei es en el año 1903, y lo hace dentro de un texto oficial del gobierno, publicado para ser manejado en las escuelas de enseñanza primaria, Jinjō shō gakkō dokuhon (Manual básico para escuela primaria). De la belleza de cada uno de estos lugares no cabe dudar, pero si procede interrogarse sobre por qué precisamente es a partir de 1903 cuando se insertan dentro de un texto oficial para la enseñanza infantil. Cuando esto sucede estamos ya en la última década de la era Meiji (1868-1912), años en los que se estaba produciendo una intensa búsqueda de la identidad, como reacción a la expansiva occidentalización que estaba en marcha en todo el país desde mediados de los años cincuenta del siglo XIX.

Sin duda alguna, subyace en ello la influencia de las ideas expuestas por el periodista y geógrafo, Shiga Shigetaka (1863-1927), ${ }^{11}$ en su tratado geográfico Nihon

5 Conan, Michel (1992): "Eloge du palimpseste", en Hypothèses pour une troisième nature. Coracle Press: Londres, p. 51; Mitchell, William J.T. (1994): Landscape and Power. Chicago: Chicago University Press, pp. 193-223

6 Yabuki, Katsuji (1952): "Scenic Trio of Japan”, en Japan. The Pocket Guide. Tokio: Japan Travel Bureau (1 $1^{\text {a }}$ ed. 1948).

7 También se le conoce como Hayashi Gahō. Neoconfuciano perteneciente al clan Hayashi. Su padre Hayashi Razan, fundó la escuela confuciana que guiaba el gobierno de los Tokugawa. El sucedió a su padre en dicha escuela y en su puesto de consejero del sogún. Continuó la tarea iniciada por su padre de recoger la historia de Japón publicando en 1670 los 310 volúmenes de Honchō-tsugan (Compilación de la historia de Japón)

8 Originalmente con este término se referían a informes regionales que comprendían aspectos de su historia, mitología, geografía, etc. Fue la emperatriz Genmei la primera que los solicitó mediante un edicto en el 713

$9 \quad$ Nihonshi Daijiten (1992-1994). Tokyo: Heibonsha, pp.584-585.

10 Kokushi Daijiten (1979-1997). Tokyo: Yoshikawa Kôbunkan, pp. 172-173 (1 $1^{\mathrm{a}}$ ed. 1927)

11 Toyosawa, Nobuko (2013): “An Imperial Vision: Nihon fûkeiron (On the Landscape of Japan, 1894) and Naturalized Nature". Studies on Asia, Series IV, Vol. 3, No. 1, pp. 25-64. 
fûkeiron o Teoría del paisaje japonés. ${ }^{12}$ Un trabajo en el que sugiere un modo diferente de ver el paisaje japonés, y lo hace con un perseguido rigor científico, buscando el valor literario de los textos, y anotando frecuentes alusiones a las manifestaciones artísticas que la singularidad del paisaje japonés es capaz de inspirar: "[...] si quisieran producir obras maestras sin precedentes, únicas en el mundo, deberían buscar temas únicamente en las cosas peculiares de Japón... Deberían dedicar toda su energía exclusivamente al vapor de agua de Japón, los volcanes (activos o durmientes), las rocas volcánicas, y la violenta erosión de las corrientes de agua." 13

Shiga consiguió formular una valoración de la geografía japonesa con la que despertar la conciencia y el orgullo nacional, al ofrecer al lector evidencias concretas de la excelencia y el carácter único de Japón, de su "esencia nacional" (kokusui shugi). Esto es lo que podemos entrever que está detrás de la potenciación del tema del Nihon Sankei en los libros de texto en 1903. Utilizar estos paisajes como un potente símbolo de identidad.

Debemos tener en cuenta que dichos paisajes son lugares muy emblemáticos en el desarrollo de sus tradiciones. Y llegado el momento, de ellos se rescatan sus raíces para ser enarbolados como emblemas identificativos de lo japonés.

En Amanohashidate, situado en la bahía de Wakasa, encontramos referencias a la cosmogonía japonesa, cuando los dioses bajaron a ordenar el caos que era la tierra. Su nombre significa "el puente del cielo". Según el Kojiki (712) y el Nihon shoki (720), la deidad Izanagi construyó un puente entre la tierra y el cielo. Desde él, hundiendo una y otra vez su venablo, los dioses conformaron el archipiélago japonés. ${ }^{14}$ Un día Izanagi se quedó dormido en la tierra y no regresó al cielo antes de que la noche lo hubiera cubierto todo. El puente se derrumbó, convirtiéndose en una larga barra de arena que se conoce con el nombre de Amanohashidate, ${ }^{15}$ La unión entre el cielo y la tierra quedó así cortada para siempre.

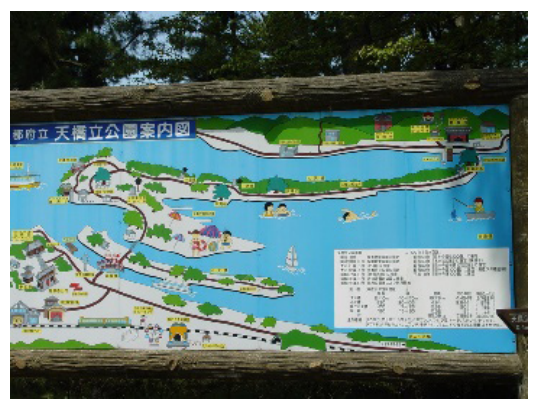

Fig. 4, Mapa de lugares y actividades de Amanohashidate, ciudad de Miyazu ,en la prefectura de Kioto. (C) (Pilar Cabañas, 2008)

12 Es la primera obra que describe a Japón desde la perspectiva de la geografía regional. Se convirtió en un best-seller, y Shiga Shigetaka se transformó en un personaje tan popular como Fukuzawa Yukichi (1835-1901), el pensador más influyente de la era Meiji.

13 Citado en Anzai, Shin-ichi (2009): "Unmediated Nationalism: Science and Art in Shigetaka Shiga's The Japanese landscape (1894)". Journal of the Faculty of Letters, The University of Tokyo, Aesthetics, Tokyo, № 34, pp. $65-81$, p. 71.

14 Según el Kojiki (712), a estos dioses se les envió a poner orden en el caos. Utilizando un venablo que fueron hincando en la masa informe que se abría ante ellos, iban dejando caer las gotas de barro adheridas en su punta, creando así las islas japonesas.

15 La longitud de esta barra de arena es de 3,6 km., y su anchura varía desde los $20 \mathrm{~m}$. a los $170 \mathrm{~m}$. Cerca de unos 8.000 pinos pueblan esta barra. 
De este modo que observa que Amanohashidate está íntimamente unido al mito fundacional de Japón, dado que Izanagi e Izanami son los padres de la diosa Amaterasu, aquella que entregó los emblemas sagrados del poder (espejo, espada y las joyas) a su nieto Ninigi convirtiéndolo en emperador con estas palabras: "Vástago soberano, ¡te la confío! ¡Ve y gobiérnala! ¡Vete! Que prospere el divino linaje y, como los cielos y la tierra, ique no tenga fin!"’16

Por ello Amanohashidate es un lugar directamente relacionado con la doctrina de la divinidad del emperador, y no debe resultar sorprendente que con la restauración del poder al emperador Meiji, se iniciara una recuperación de todo aquello que justificaba la posición que él ocupaba. Por esta razón, el sintoísmo, sin convertirse oficialmente en la religión del estado, fue utilizado para movilizar las lealtades imperiales en favor de la construcción de una nación moderna. ${ }^{17}$

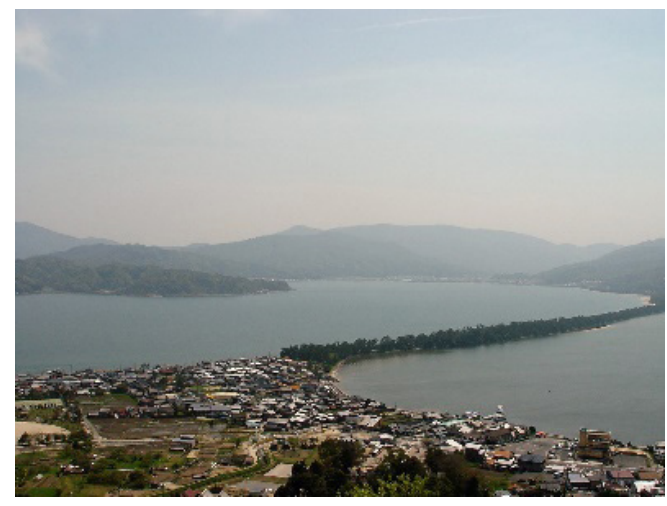

Fig. 5, Vista de Amanohashidate, ciudad de Miyazu, prefectura de Kioto. (C) (Pilar Cabañas, 2008)

Otro de estos paisajes es la bahía de Matsushima, Islas de los pinos, situado al nordeste de Japón, en la prefectura de Miyagi. Visto desde tierra firme, o contemplado desde una barca, los cerca de 260 islotes que salpican la bahía son de una belleza sorprendente.

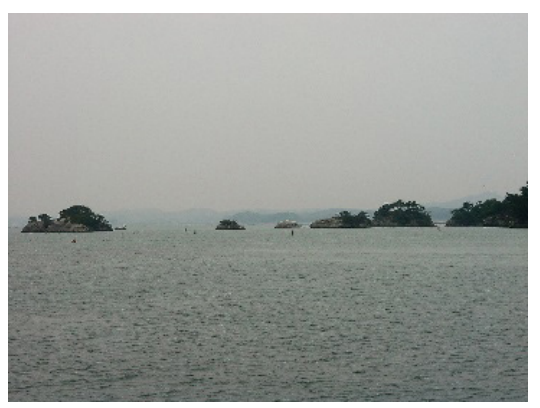

Fig. 6, Vista de Matsushima, en la prefectura de Miyagi. (C) (Pilar Cabañas, 2008)

Gardini, Walter (1995): Religiones y literatura de Japón. Buenos Aires: Kier, p. 28

17 Fridell, Wilbur M. (1979): “A Fresh Look at State Shintō”. Journal of the American Academy of Religion, 44, 3, Oxford, pp. 547-561, p. 548. 
El maestro de haiku Matsuo Bashō (1644-1694) asombrado ante su panorámica se quedó sin palabras:

"Islas sobre islas, miles de esquirlas estallan en el mar del verano" [shimajima ya /chiji ni kudakete / natsu no umi]..$^{18}$

Y varios siglos antes Fujiwara no Shunzei (1114-1204) escribió este otro poema:

"Regresando una vez más a contemplar Matsushima, las olas en Ojima azotan mi ajado sombrero" [tachi kaeri / mata mo kite min / matsushima ya / ojima no tomaya Inami ni arasu na].

Son numerosos los poemas compuestos en torno a la emoción despertada por este lugar. Olas que estallan, que se retiran para regresar. Olas que nos desgastan y nos conmueven. Una contemplación que penetra por todos nuestros poros para, como decía el pedagogo, ensayista y filósofo Francisco Giner de los Ríos (1839-1915), conmovernos, formarnos, transformarnos. ${ }^{19}$

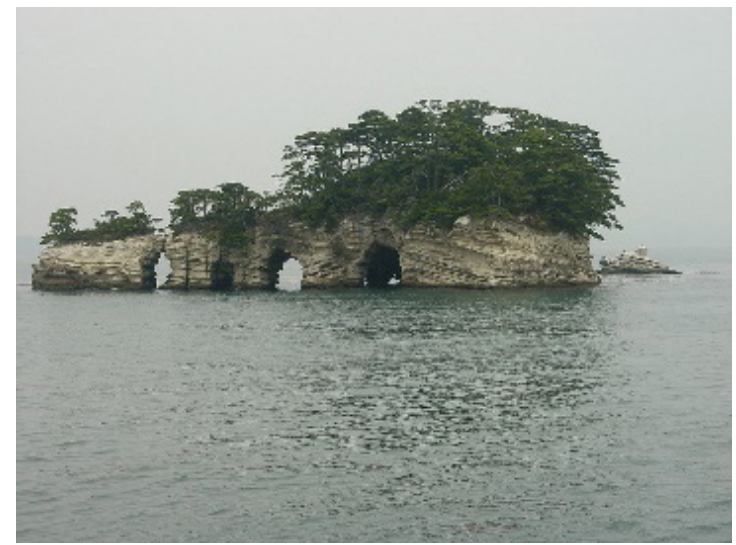

Fig. 7, Vista de Matsushima, en la prefectura de Miyagi. (C) (Pilar Cabañas, 2008)

Mirando hacia los numerosos islotes, se levanta uno de los templos budistas más antiguos del país, Zuigan-ji. Fundado en 828, fue reconstruido en 1609 por Date Masamune convirtiéndolo en un importante templo de la escuela Zen. ${ }^{20}$ Pero, como en el caso de Amanohashidate, en la bahía de Matsushima, uno puede recrear el surgimiento del archipiélago japonés imaginando que aquellas islas rocosas son el resultado de las gotas de barro caídas del venablo de Izanagi, y que en su singularidad, cada una de ellas podría estar marcada como un lugar sagrado con un shimenawa.

En el extremo suroeste de Honshū, se localiza el tercer paisaje del Nihon Sankei, la isla de Miyajima. Se halla cerca de la ciudad de Hatsukaichi, en la Prefectura de Hiroshima. Es una de las muchas islas del mar Interior de Seto, y en ella se yergue el monte más elevado de la región, el monte Misen (530 m.), cubierto por un bosque virgen de

18 http://www.vianegativa.us/2011/03/matsushima-ya/ [Consulta: 10/9/2016]

19 Ortega Cantero, Nicolás (2003): "La visión del paisaje de Francisco Giner de los Ríos". Boletín de la Biblioteca del Ateneo, segunda época - año IV nº 13, Madrid, pp. 21-30. http://www.juntadeandalucia.es/educacion/ vscripts/wginer/w/rec/3088.pdf [Consulta: 10/10/2017]

20 Su Sala de los pavos reales goza de la calificación de Tesoro Nacional, mientras que el o-nari-mon ("puerta de honor") y el naka-mon ("puerta interior") son consideradas Importante Bien Cultural/ Bien Cultural Destacado. 


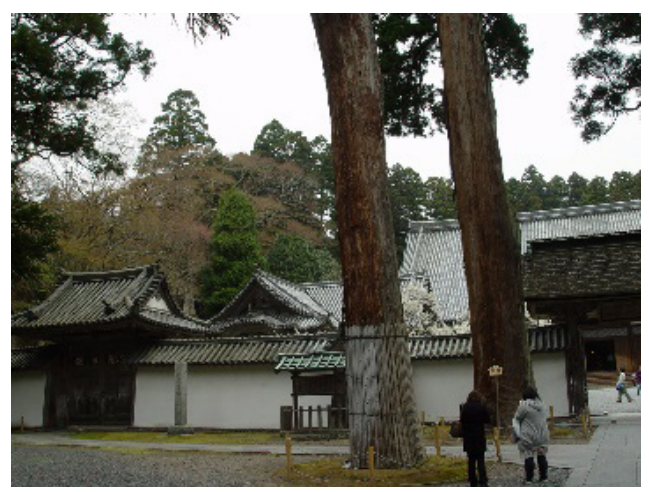

Fig. 8, Zuigan-ji, templo budista fundado en 828 y reconstruido en 1609 por Date Masamune. Matsushima, prefectura de Miyagi. (C) (Pilar Cabañas, 2008)

pinos. ${ }^{21}$ Se trata de un lugar de nuevo relacionado con el sintoísmo, religión que consideró sagrada la isla y su montaña, de ahí el nombre de Miyajima, "Isla Santuario". Por esta razón se prohibió en ella la presencia humana. Este hecho motivó el que el santuario allí construido, Itsukushima, se levantara, no en tierra firme, sino sobre el agua. Se considera que el santuario fue fundado en el 593 en honor de las deidades del mar, pero no hay rastro de su existencia hasta que las fuentes documentales hablan de él en el siglo IX y registran que los Taira, uno de los clanes más poderosos del periodo, lo reconstruyeron en el siglo XI.

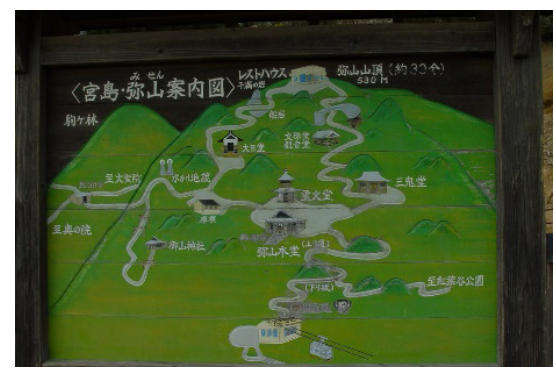

Fig. 9, Mapa turístico del monte Misen en la isla de Miyajima, prefectura de Hiroshima. C (Pilar Cabañas, 2008)

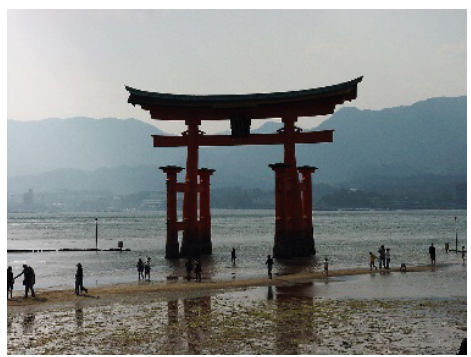

Fig. 10, Torii del santuario de Itsukushima. Isla de Miyajima, prefectura de Hiroshima. (C) (Pilar Cabañas, 2008)

${ }^{21}$ Su conjunto está inserto en la actualidad el Parque Nacional de Setonaikai. 
El fuego y las catástrofes naturales han azotado con frecuencia el lugar, de modo que la mayoría de los edificios que hoy contemplamos datan estructuralmente de 1241, y elementos más expuestos como el torii, han sufrido diversas reconstrucciones, siendo éste intervenido por última vez en 1875.

Con sus alas simétricas, sus galerías y la plataforma para las danzas, el santuario de Itsukushima refleja la influencia de la arquitectura de los palacios de los Tang y de los pabellones budistas del paraíso. Así, en este santuario las construcciones más significativas son el honden (edificio principal y santuario), el haiden (oratorio) y el heiden (edificio de las ofrendas) alineados con el gran torii. Enfrente está el hirabutai o plataforma ceremonial, donde tienen lugar las danzas ceremoniales kagura. Del hirabutai parten dos corredores, uno hacia el este y otro hacia el oeste, que lo conectan con los edificios secundarios del templo.

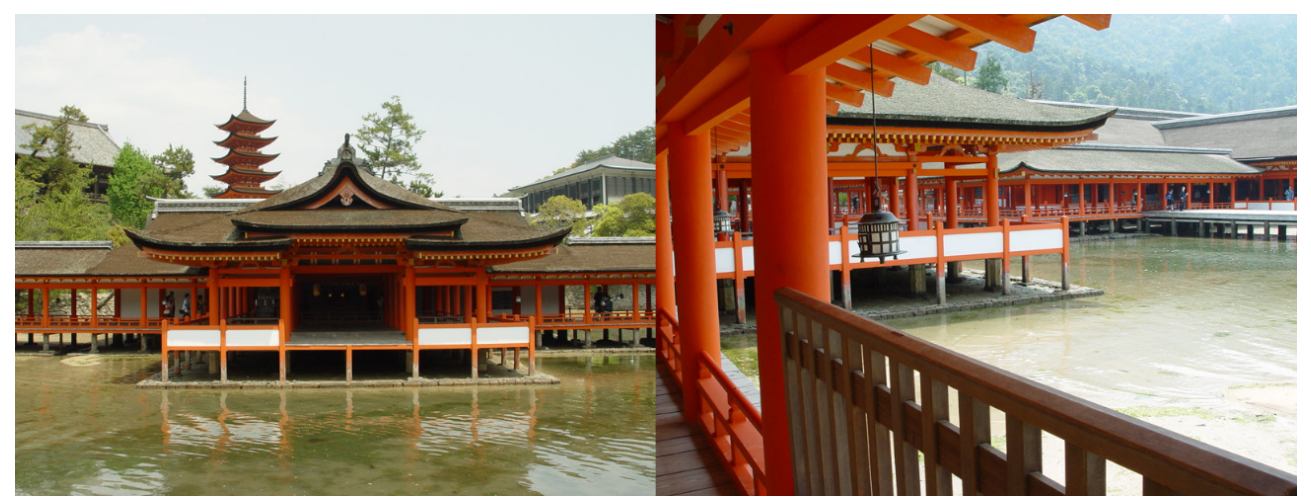

Fig. 11, Santuario de Itsukushima, la mayoría de los edificios que hoy contemplamos datan estructuralmente de 1241. Isla de Miyajima, prefectura de Hiroshima. (C) (Pilar Cabañas)

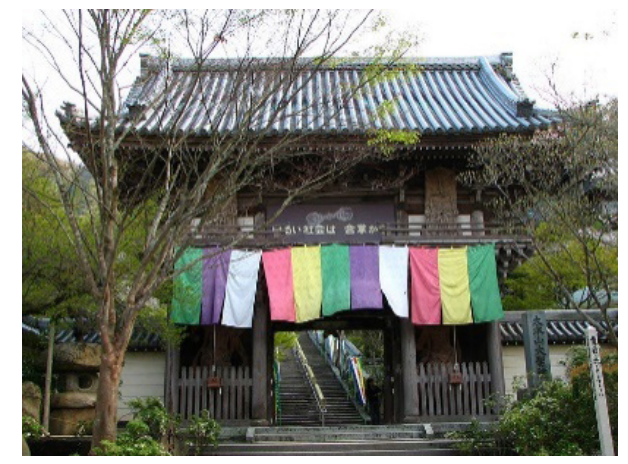

Fig. 12, Niōmon, puerta custodiada por dos reyes guardianes que da acceso al templo budista Daisho-in, fundado en el 806. Isla de Miyajima, prefectura de Hiroshima (C) (Pilar Cabañas, 2008)

El lugar es más espectacular si cabe con la marea alta y a la caída de la tarde, cuando las luces de los pasillos de sus colgantes faroles de bronce, se encienden.

A estas construcciones de culto sintoísta, en el 806, se sumó junto a la montaña sagrada un templo budista, Daishō-in. Este, erigido por orden del fundador de la es- 
cuela budista Shingon, Kūkai (774-835), conocido póstumamente como Kōbō-Daishi, se convirtió en el número catorce del camino de peregrinación conocido como Chūgoku Sanjūsan Kannon Reijōo (El camino de peregrinación de Kannon en la región de Chūgoku), en el que se visitan 33 templos dedicados al bosatsu Kannon. Con ello la isla, al ser considerada lugar de peregrinación, fue perdiendo aquel carácter restringido. Se convirtió entonces en un enclave religioso doblemente vinculado a lo sagrado, de desbordante belleza, no sólo por el entorno natural, sino por la maravillosa integración paisajística de sus edificios religiosos. Arquitecturas levantadas por la mano del hombre, pero que realzan la belleza natural poniendo sobre sus aguas azueles toques de color rojo y blanco, que contrastan con el fondo verde de la vegetación. Aproximándonos a la isla se recorta el torii rojo, que capta nuestro foco de interés y marca como sagrado el venerado paisaje.

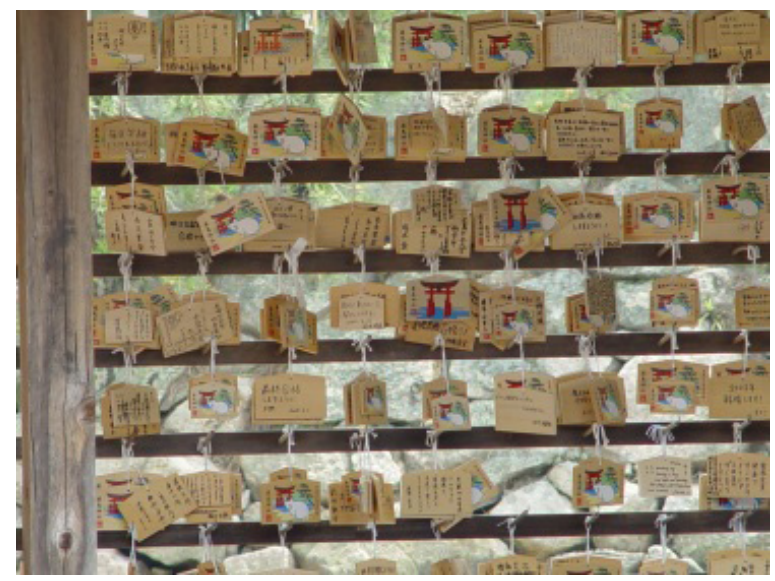

Fig. 13, Ema, placas de madera ofrecidas a modo de peticiones a los kami. santuario de Itsukushima, isla de Miyajima, prefectura de Hiroshima. (C) (Pilar Cabañas, 2008)

Siendo Miyajima una de las islas sagradas del sintoísmo, forma parte de un paisaje ligado al poder de los Taira, uno de los clanes más importantes del periodo Heian. Los fundadores de este clan, fueron miembros colaterales de la familia imperial. Por ello su posicionamiento entre los clanes y en la corte tuvo siempre gran peso y relevancia. En ocasiones se usa la lectura de los ideogramas del nombre, siendo entonces también conocidos como Heishi o Heike. El clan cobró importancia a ojos del emperador por ser capaces de controlar a los piratas que merodeaban por el mar interior de Seto, que es donde se sitúa la isla. Fue a finales del período Heian cuando Taira no Kiyomori (1118-1181) apoyó al emperador Go-Shirakawa frente a una rebelión. Vencedores, constituyó el primer gobierno bajo el consejo y el dominio de los samuráis en la historia de Japón. Es por todo ello que este paisaje está ligado a los inicios del poder de la clase guerrera, que llega a enfrentarse en Kioto, la capital imperial, a la burocrática aristocracia de corte de los Fujiwara.

Tanto para los japoneses como para los viajeros de más allá de los mares, fueron el protagonismo de estos enclaves históricos y literarios presente en las publicaciones, realzado por las imágenes que en ocasiones ilustraban sus referencias, los que juntos despertaron los deseos de experimentarlos. 


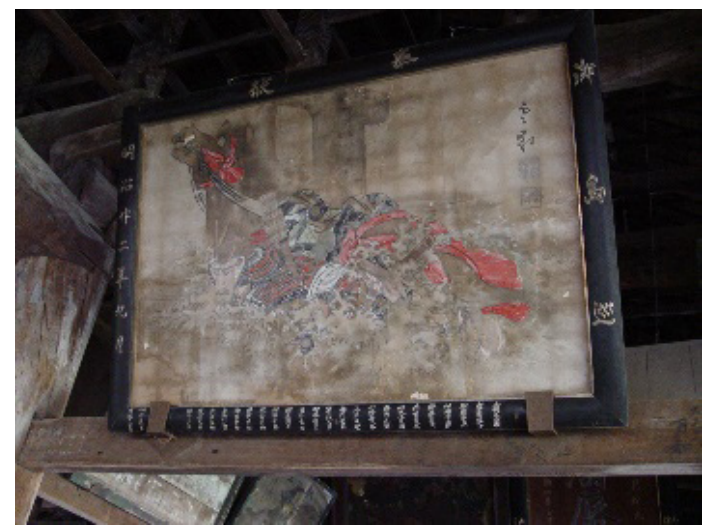

Fig. 14, Pintura votiva con tema de guerrero en el interior del templo budista de Senjōkaku. Isla de Miyajima, prefectura de Hiroshima (C) (Pilar Cabañas, 2008)

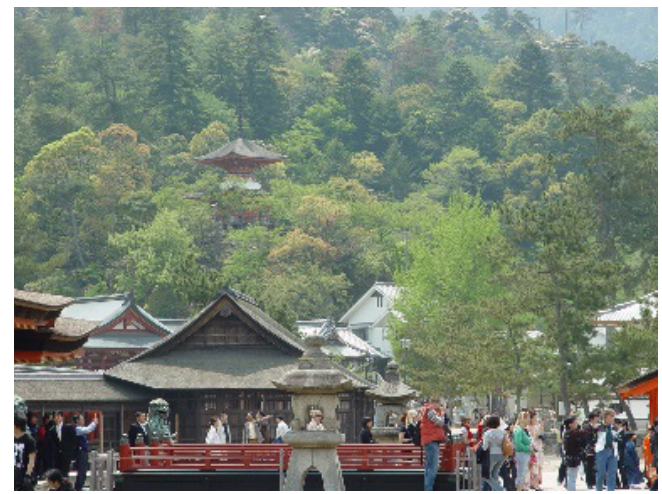

Fig. 15, Isla de Miyajima, prefectura de Hiroshima. C (Pilar Cabañas, 2008)

En el siglo XIX, la imagen fue la gran protagonista, y el grabado y la fotografía fueron los responsables de remarcar estos lugares en los itinerarios de los turistas como "deseables", convirtiéndose la barra de arena con los pinos, las rocas en simbiosis con los árboles y el torii rojo en la bahía en sus highlights. Y al mismo tiempo, conforme se fue desarrollando el turismo en las zonas de un modo masivo, las postales y los souvenirs (llaveros, cucharas, trapos de cocina etc.), como viene siendo habitual en la promoción de un lugar, adoptaron las imágenes de estos highlights como emblemas, trasladando con su regalo a otros el deseo de conocerlo, y atrapando en su presente, a través del objeto, la realidad vivida.

Estos tres paisajes, los Nihon Sankei, a pesar de los cambios técnicos y culturales, de la renovación de las sensibilidades, han mantenido su protagonismo a lo largo de los siglos, enriqueciendo su significado.

Ciertamente las nuevas construcciones que en su entorno se fueron levantando a lo largo del tiempo los modificaron, los peregrinos y turistas que allí llegan los alteran, pero a la vez, gracias a ellos cobran existencia y presencia histórica, religiosa, literaria e incluso artística. Las evocaciones de su existencia en la poesía, en las novelas, o en el recontar de quienes los vieron con sus propios ojos, han construido su ser, que va más allá de su presencia física en un rincón de la geografía del país. 
Tal y como postula Michel Conan, debemos considerar que lo que nos ofrecen no es una visión panorámica del lugar al estilo del Renacimiento, sino paisajes recubiertos de múltiples escrituras. ${ }^{22}$

Han sido precisamente sus estratos culturales, y no exclusivamente su "ser bella escenografía", lo que ha conseguido que se mantengan durante siglos en la realidad colectiva del país como un ancla, como una seña de identidad frente a las turbulencias y embates de los cambios, la modernidad y la posmodernidad.

Podríamos pensar que, en ellos, en su conjunto, se resume buena parte de lo que identificamos como auténticamente japonés: el sintoísmo, el samurái y el zen. Una verdadera configuración del cognitive associational map, que el conjunto de la sociedad japonesa ha compuesto gracias a su uso social, y que lleva algo más de un siglo proponiéndonos a todos aquellos que movidos por la curiosidad y el deseo de descubrimiento de otras realidades nos acercamos desde el exterior. 